\title{
MEDIADOULA: ATENÇÃO AO(À) VISITANTE DA EXPOSIÇÃO SENTIDOS DO NASCER $^{1}$
}

\author{
Bernardo Jefferson de Oliveira \\ Faculdade de Educação - UFMG \\ bjo@ufmg.br \\ Juliana Prochnow dos Anjos \\ Faculdade de Educação - UFMG \\ juproch9@gmail.com \\ Sônia Lansky \\ Mestrado Profissional - UFMG \\ sonialansky@gmail.com
}

\section{RESUMO}

A experiência da exposição Sentidos do Nascer ressalta a importância da escuta-acolhimento como uma das dimensões essenciais da mediação museal. Essa exposição tem o objetivo de contribuir para a mudança da percepção da sociedade sobre o nascimento, incentivando a valorização do parto normal. Neste artigo descrevemos a interação com o público, relacionando a função de mediador(a) às características do trabalho das doulas. Assim, criamos o termo mediadoula para representar essa atividade e argumentamos sobre sua relevância. Para contextualizar essa experiência, descrevemos a exposição Sentidos do Nascer, seus propósitos e abordagem.

Palavras-chave: Mediadores. Doula. Exposição sobre parto.

\section{MEDIADOULA: ATTENTION TO THE SENSE OF BIRTH VISITORS}

\begin{abstract}
The experience of the exhibition Senses of Birth highlights the importance of listening and welcoming as essential dimensions of museum mediation. This exhibition aims to contribute to the change of the perception of society on birth, encouraging the valuation of normal delivery. In this article we describe the interaction with the public, relating the role of museum mediator to the characteristics of doulas work. Thus, we create the term mediadoula to represent this activity, and advocate its relevance. To contextualize this experience we describe the exhibition Senses of Birth, its purposes and approach.
\end{abstract}

Keywords: Mediators. Doula. Childbirth.

\section{MEDIADOULA: ATENCIÓN AL VISITANTE DE LA EXPOSICIÓN SENTIDOS DEL NACER}

\footnotetext{
${ }^{1}$ Este trabalho contou com o apoio financeiro do CNPq, do Ministério da Saúde, da Fundação Bill e Mellinda Gates e da Fundação de Amparo à Pesquisa de Minas Gerais (FAPEMIG).
} 


\section{RESUMEN}

La experiencia de la exposición Sentidos del Nacer destaca la importancia de la escucha-acogida como una de las dimensiones esenciales de la mediación del museo. Esta exposición tiene como objetivo contribuir al cambio de la percepción de la sociedad sobre el nacimiento, fomentando la valoración del parto normal. En este artículo describimos la interacción con el público, relacionando el papel del mediador del museo con las características del trabajo de las doulas. Por lo tanto, creamos el término mediadoula para representar esta actividad, y abogamos por su relevancia. Para contextualizar esta experiencia describimos la exposición Sentidos del Nacer, sus propósitos y enfoque.

Palabras clave: Mediadores. Doula. Exposición sobre el parto.

"MEDIADOULA: ATTENTION AU VISITEUR DE L'EXPOSITION SENS DE LA NAISSANCE"

\section{RÉSUMÉ}

L'expérience de l'exposition Sens de la Naissance met en évidence l'importance de l'écoute et de l'accueil en tant que dimensions essentielles de la médiation muséale. Cette exposition a pour objectif de contribuer au changement de perception de la société à la naissance, en encourageant la valorisation de l'accouchement normal. Dans cet article, nous décrivons l'interaction avec le public, reliant le rôle de médiateur de musée aux caractéristiques du travail des doulas. Ainsi, nous créons le terme mediadoula pour représenter cette activité et plaider pour sa pertinence. Pour contextualiser cette expérience, nous décrivons l'exposition Sens de la Naissance, ses buts et son approche.

Mots-clés: Médiateurs. Doula. Exposition à l'accouchement.

\section{INTRODUÇÃO}

O Brasil é campeão mundial em cesáreas desnecessária, a maior parte programadas antes do trabalho de parto $^{2}$. Promover a assistência humanizada ao parto e nascimento e disseminar informações adequadas para se assegurar o tempo de nascer natural de cada criança é, portanto, uma medida importante em saúde pública. Muitas iniciativas vêm trabalhando nessa direção e a exposição Sentidos do Nascer é mais uma, com o objetivo de contribuir para a mudança da percepção da sociedade sobre o nascimento, incentivando a valorização do parto normal.

\footnotetext{
${ }^{2}$ São chamadas cesarianas desnecessárias aquelas realizadas por conveniência dos obstetras ou das gestantes, e não por indicações médicas reais. Com bases em estudos epidemiológicos e evidências científicas, a Organização Mundial de Saúde (OMS) considera que as cirurgias de cesariana necessárias não passam de 15\% do total de partos. No Brasil este índice chegou a 56,7\% em 2014. DATASUS/MS, 2016.
}

Rev. Iberoam. Patrim. Histórico-Educativo, Campinas (SP), v. 4, n. 2, p. 325-342, jul./dez. 2018 
O projeto de educomunicação centrado na exposição Sentidos do Nascer é fruto de uma parceria da UFMG com a Prefeitura de Belo Horizonte, com recursos advindos do edital do CNPq/Ministério da Saúde/Fundação Bill e Melinda Gates ${ }^{3}$. Trata-se de uma pesquisa-intervenção que avalia os efeitos da exposição interativa e itinerante na percepção dos visitantes (público em geral) para dimensionar seu potencial na transformação da cultural sobre o parto ${ }^{4}$. A exposição, que percorreu cinco cidades (Rio de Janeiro, Belo Horizonte, Niterói, Ceilândia e Brasília) e recebeu 28.682 visitantes em 2015, foi instalada em contêineres para facilitar sua circulação e montagens em praças, parques e feiras. Seu objetivo não era apenas informar, mas colocar em debate o assunto e as controvérsias envolvidas, convidando o(a)s visitantes a vivenciar o nascimento e a ressignificar os sentidos do nascer. Dessa forma, essa exposição exige mais do que textos informativos nas paredes e guias preparados para transmitir dados e conteúdos. Exige escuta, sensibilidade, acolhimento e abertura para o diálogo. É disso que trataremos nesse texto.

\section{INTERAÇÃO PÚBLICO-EXPOSIÇÃO}

A expografia Sentidos do Nascer foi inspirada nas discussões que tratam das formas de interação público-exposição, e teve como perspectiva a "implicação dos sujeitos". Para tanto, conjuga diferentes linguagens, de arte-digital com técnicas teatrais e suportes como vídeos, fotografias, cenários e textos em painéis, de forma a despertar diferentes sensações no(a)s visitantes. Um dos pressupostos adotados é que a arte é capaz de provocar outro tipo de experiência e reflexão. Imersiva e interativa, a exposição Sentidos do Nascer foi desenvolvida para sensibilizar, gerando emoções através da arte, instigando de forma lúdica, provocando o desejo de conhecer e o pensamento crítico sobre a banalização da cesariana, sobre a medicalização da vida e a postura consumista na saúde.

\footnotetext{
${ }^{3}$ Edital no 05/2013 MCTI/CNPq/MS/SCTIE/Decit/Fundação Bill e Melinda Gates, com aprovação no Comitê de Ética da UFMG - CAAE-39525114.8.1001.5149.

${ }^{4}$ A partir dessa experiência de itinerância com os contêineres, foram desenvolvidas duas montagens de exposições fixas e de longa duração: Uma no Parque da Mangabeiras, em Belo Horizonte, e outra no Centro Cultural do Ministério da Saúde, no Rio de Janeiro.
} 
Imagem 1 - planta baixa da exposição Sentidos do Nascer, com suas diferentes seções.

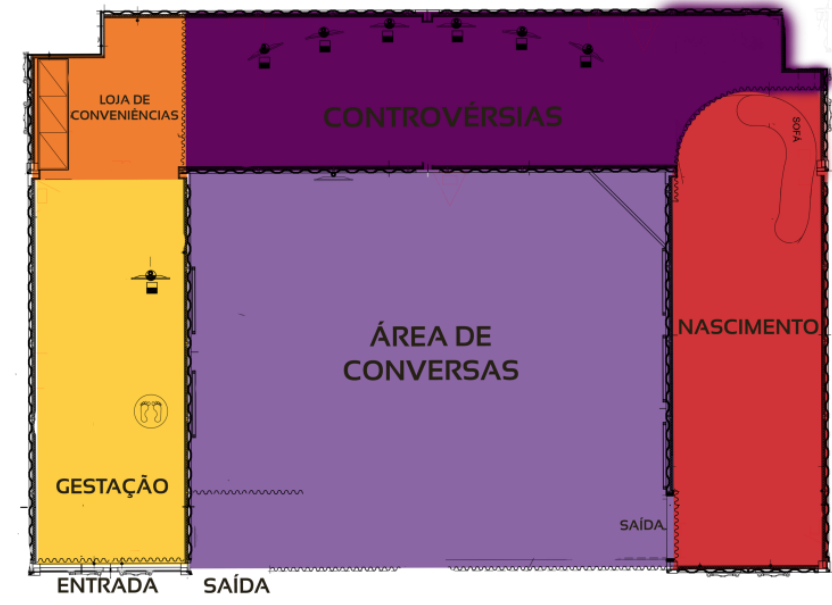

Fonte: Exposição Sentidos do Nascer.

A exposição é estruturada em cinco seções, adaptadas em quatro contêineres, com uma cobertura de uma tenda de lona sobre estes. Logo na entrada, no ambiente chamado Gestação, o(a) visitante se vê numa grande tela de TV com um bebê projetado em sua barriga, para dar início ao seu envolvimento com este acontecimento impactante da vida: “estou grávida(o), meu bebê está pronto para nascer, e agora?”. O(A) visitante é convidado(a) a registrar este momento em fotografia e compartilhar a novidade nas redes sociais. Neste momento o(a) mediador(a) lhe felicita e a visita prossegue; o(a) visitante se mantém grávida(o), representação feita por meio de um adesivo de um bebê colocado em sua barriga, de modo que se engaje simbolicamente e pense sobre o seu parto e no nascimento ao longo da exposição. Em seguida, o Plano de Parto é apresentado ao(à) visitante, em um folheto ${ }^{5}$ que traz informações sobre as possibilidades de cuidado durante o parto, informações sobre as práticas assistenciais recomendadas e seus direitos de escolha. Segue-se então para o segundo ambiente, a Loja de Conveniências da Maternidade Cirúrgica, uma caricatura da mercantilização do parto onde gôndolas de supermercado com produtos "irresistíveis" e promoções de partos programados são ironicamente oferecidos ao(à)s visitantes.

\footnotetext{
${ }^{5}$ Material desenvolvido pelo movimento $\mathrm{BH}$ pelo Parto Normal, divulgado para as gestantes como oportunidade para se informarem sobre práticas recomendadas na atenção ao parto e direitos de escolha, como acompanhante, posição no parto, métodos de conforto, entre outros.
} 
Imagem 2 - Ambiente "Loja da Maternidade Cirúrgica", exposição Sentidos do Nascer, 2015.

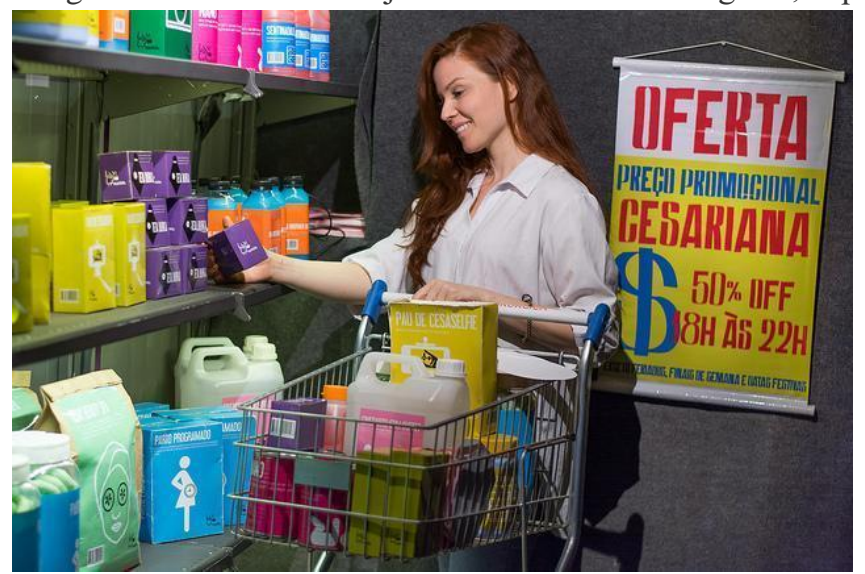

Fonte: Fotografia de Thiago Castellan. Os produtos expostos com contorno caricatural - "Big Brother do Bebê", "Sentinadolol", "Spa Mamy Beauty", "Teta Burka" etc. - foram inspirados em ofertas reais.

Em um terceiro ambiente, Controvérsias, o(a)s visitantes são exposto(a)s a opiniões divergentes e palpites diversos sobre a melhor forma de nascer. Atores e atrizes no papel de profissionais e familiares aparecem em tamanho real em seis telas grandes de TV, debatendo sobre a forma de nascer, suas visões e vivências com o parto normal e a cesariana, reproduzindo o debate atual na sociedade brasileira, preconceitos, desinformação, assim como posicionamentos que questionam as práticas vigentes.

Imagem 2 - Ambiente “Controvérsias”. Exposição Sentidos do Nascer. 2015.

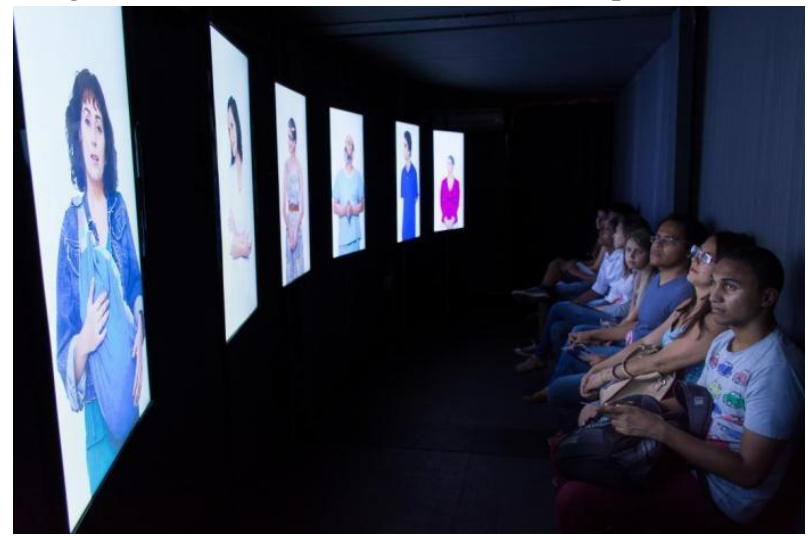

Fonte: Fotografia de Thiago Castellan.

Após acompanharem o debate, o(a)s visitantes são acolhidos em uma sala-útero gigante aconchegante e quente, onde vivenciam um conjunto de experiências sensoriais sobre o nascimento: sentam-se no sofá-placenta ao som dos batimentos do coração da mãe, se enlaçam no cordão umbilical e escutam a voz de um bebê pedindo delicadamente para mãe esperar o seu 
momento de nascer. Em seguida, quando se sentem pronto(a)s, passam por um corredor equivalente ao canal vaginal, estreito e macio, para enfim "nascerem". Saem então pela vagina e se deparam com uma imagem enorme de uma mãe feliz e acolhedora, esperando o(a)s visitantes com os braços abertos $^{6}$.

Chegam então ao quinto e último ambiente, onde estão dispostos painéis e vídeos informativos, configurando-se como um local que possibilita encontros, trocas de experiências e conversas. Assim, neste ambiente se concretiza a estratégia da exposição de instigar a curiosidade do(a) visitante, estimulando a busca por mais informações ao final do percurso para que tenha a oportunidade de aprofundar sua própria experiência e visão sobre o tema. Nesta seção são apresentados textos curtos, imagens e indagações sobre as questões de fundo que envolvem o contexto do parto no Brasil. São elas: o tempo e a pressa da sociedade contemporânea, a história da assistência ao parto e o deslocamento do protagonismo da mulher, informações sobre o parto normal e o significado da dor, o contrapondo dor e sofrimento, a violência obstétrica e infográfico sobre índices de cesarianas de diversos países do mundo e do Brasil, dos estados e das principais maternidades da cidade onde a exposição está montada ${ }^{7}$. Esse ambiente conta com sofás e pufes aconchegantes que convidam o(a) visitante a se sentarem com calma e usufruírem do momento. Trata-se de um espaço onde tecidos leves e esvoaçantes impressos com imagens impactantes e inspiradoras mostram mulheres, bebês e homens envoltos em um clima de afeto e magia em momentos de partos.

6 Uma visão geral sobre a exposição pode ser acessada em reportagens televisivas como $<$ https://www.youtube.com/watch?v=CYAaR538EuM\&t=2s > $<$ https://www.youtube.com/watch?v=n2sy7DGZsuk\&t=3s>.

7 Os textos, fotos e infográfico utilizados na exposição ficam também disponíveis no sítio <http://www.sentidosdonascer.org/exposicao/conversas/> e no catálogo, editado pelo. Ministério da Saúde (BRASIL, 2015). Disponível em: <http://www.sentidosdonascer.org/blog/2016/03/catalogo-da-exposicao/>. 
Imagem 4 - Ambiente "Conversas" da exposição Sentidos do Nascer, 2015.

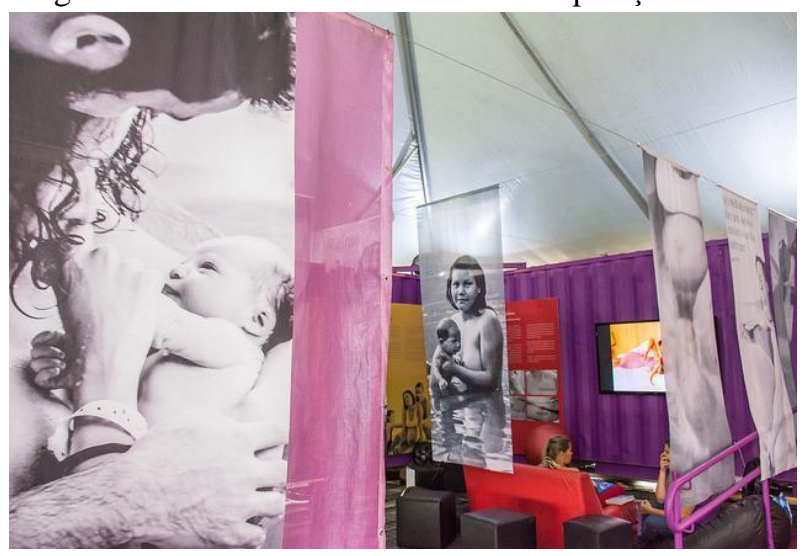

Fonte: Fotografia de Thiago Castellan.

\section{FORMAÇÃO DE MEDIADORE(A)S}

Em função da circulação da exposição Sentidos do Nascer em diferentes cidades e da importância de prepararmos o(a)s mediadore(a)s em cada localidade, desenvolvemos um curso na plataforma moodle de 30 horas de Educação a Distância antes dos ensaios presenciais. Alguns princípios norteadores para a formação do(a)s mediadore(a)s foram considerados, por exemplo, o de que a mediação não deve se pautar na transmissão de informação, mas em diálogos significativos (CONTIER, 2018). Aos poucos percebemos as especificidades dos perfis e habilidades mais adequadas para a mediação dessa exposição. A equipe principal, composta por estudantes universitário(a)s de diversas áreas do conhecimento, tem a proeminência de estudantes de enfermagem. Vário(a)s são bolsistas, mas sempre contamos com a participação de voluntário(a)s, ativistas do parto normal ou interessados em ter uma experiência formativa diferente ${ }^{8}$.

São várias as denominações - guia, monitor(a), educador(a), intérprete, tradutor(a), explicador(a), comunicador(a) - relacionadas aos diferentes papéis que o(a) mediador(a) pode desempenhar em uma exposição. Às vezes o papel de mediação é conjugado com a função de recepcionista e de zelador(a), evitando que visitantes façam mal uso dos equipamentos ou incomodem outro(a)s visitantes. Essas duas funções parecem menos nobres, mas se pensarmos na figura de um(a) anfitrião(ã) podemos ver a multiplicidade das suas habilidades. Um bom anfitrião está preocupado em acolher, em fazer que o(a) visitante tenha bons momentos, que aquela

\footnotetext{
${ }^{8} \mathrm{O}$ certificado de participação neste projeto de extensão da UFMG, com registro da carga horária, é um atrativo para muitos participantes.
} 
experiência seja significativa para todo(a)s o(a)s envolvido(a)s, além de cuidar para que tudo esteja funcionando bem e, para tanto, tem que atentar para muitas questões ao mesmo tempo.

No campo de conhecimento que aborda a educação em museus, tem-se preocupado muito com o processo de mediação cultural e mediação da informação, pautando-se na ideia de construção coletiva do conhecimento. A mediação humana presencial tem sido uma grande promotora de interação entre o público e os aparatos expositivos. Provocar diálogos entre visitantes e o conteúdo da exposição é um objetivo da mediação em museu e o risco a ser evitado seria o de transformar a mediação em um processo unidirecional, desconsiderando o protagonismo do(a) visitante (PINTO; GOUVÊA, 2014). A defesa pela participação e envolvimento do(a)s visitantes em museus e exposições tem sido ampla. São vário(a)s o(a)s autore(a)s que enfatizam a importância do diálogo com o público visitante (WAGENSBERG, 2005; PEREIRA, 2007; MARANDINO, 2008; DUTRA, 2012; NASCIMENTO, 2013, dentre outros).

A mediação numa exposição ou museu envolve muitos tipos de diálogos: ela é a grande promotora de interação. Podemos falar em mediação da exposição com o público, mediação entre os diferentes visitantes e mediação na troca de experiências, por exemplo. Entende-se que o diálogo vai muito além de uma interação face a face com trocas de turno de falas. Na exposição Sentidos do Nascer parte-se da ideia de que ele nem sempre é harmonioso, que pode e deve ser controverso, já que entende-se que é permeado por múltiplos pontos de vista. Acreditamos que essa tensão entre as diferenças pode propiciar uma boa alternativa aos discursos unilaterais e de ordem que têm naturalizado e difundido a prática de cesáreas em todo o país.

Queremos que as experiências do(a)s visitantes sejam significativas, emocionantes, marcantes. Assim, sugerimos que o(a)s mediadore(a)s se situem junto às seções que mais gostariam de compartilhar com o público. No entanto, todo(a)s devem se preparar para apresentar as diferentes partes da exposição. Além disso, precisam conhecer bem o conteúdo presente nos diferentes painéis e filmes que são exibidos no ambiente externo, destinado a conversas e debates com quem visita a exposição. Acreditamos ser uma boa estratégia o(a) mediador(a) convidar o(a)s visitantes a conhecer algo que para ele(a) é significativo e tocante. Por outro lado, devem estar atento(a)s e não devem se guiar somente por suas percepções e envolvimento pessoal com a temática. Muito pelo contrário, é no exercício de uma escuta ativa do(a) visitante que ele saberá que são muitas as possibilidades de conversas e percursos. 
Assim, nos processos de formação do(a)s mediadore(a)s exemplificamos que, indagar em qual maternidade da cidade o(a) visitante nasceu ou teve filho, é um convite para se verificar juntos no infográfico os índices de cesarianas das maternidades. Se na conversa uma visitante falar sobre o médico que "fez o parto", perguntar "de quem é o parto, afinal?" e ir junto ler o painel "De quem é o parto". Outra estratégia é convidar os que "acabam de nascer" a experimentarem dispositivos que auxiliam a mulher durante o trabalho de parto, disponíveis neste ambiente: a bola de nascimento, o banquinho e o tecido de parto. Se a conversa esbarrar nos mitos ou tabus sobre o parto normal e a cesariana, sugerimos indagar se o(a) visitante teve a chance de ler os totens informativos. Convidamos para tirar fotos e ajudar a compartilhar e a divulgar. Essas orientações para a mediação ganham aqui outro sentido, uma vez que estamos tratando de situações importantes das vidas das pessoas.

Exposições sobre o tema do parto e nascimento costumam representar o discurso biomédico reduzindo o tema à sua dimensão fisiológica. Tal perspectiva traz implícito um projeto biopolítico que reforça a intervenção médica sobre o comportamento social e domínio do corpo feminino e os direitos sexuais. (PALHARINI, 2015). Mesmo quando as exposições sobre o parto e nascimento incluem aspectos históricos e culturais, esses geralmente são apresentados de forma pretensamente neutra, ou mesmo folclóricas, distantes das controversas questões macro ou micro políticas.

Diferentemente, a exposição Sentidos do Nascer traz à tona as dimensões sócio-políticas e problematiza as representações sociais sobre o parto e nascimento explorando as disputas dentro do campo da saúde, das categorias profissionais, das perspectivas de gênero, étnico-raciais, dos interesses de mercado e ideologias preponderantes. Discordando de autores que consideram que "o museu enquanto instituição a serviço da cidadania não deve tomar uma posição específica: não se caracterizar como espaço de militância, mas também não se instituir como espaço de cumplicidade de discursos hegemônicos" (PALHARINI, 2015, 212), julgamos que, na abordagem de temas polêmicos, exposições podem sim adotar um posicionamentos provocativo como parte da promoção do debate público. Esse julgamento remete ao longo debate sobre as fronteiras entre perspectivas científicas e ativismo social, que ultrapassa o escopo deste artigo. Nosso foco aqui é tão somente em uma dimensão inexplorada, mas potente, da atividade prática de mediação em museus.

Como é uma exposição ligada a uma causa social que mobiliza diversas pessoas, tivemos sempre o apoio de voluntário(a)s envolvido(a)s com a promoção do parto normal ou natural e o 
empoderamento da mulher. Essa participação voluntária aconteceu tanto na atuação do(a)s mediadore(a)s e na divulgação, quanto na promoção de atividades extras na exposição, como rodas de conversas, pintura na barriga das grávidas, yoga, outras atividades e encontros temáticos. Esse ativismo tem contribuído enormemente, sobretudo porque geralmente essas ativistas são de forma geral bem informadas sobre o tema, com vivências no debate público e aguerridas. Assim sendo, comporiam, a princípio, o perfil ideal para a mediação na exposição Sentidos do Nascer. O curso de formação de mediadore(a)s procurava de certa forma subsidiar essa postura, com leituras e envolvimento nos debates em torno do parto, dos direitos, políticas públicas e articulações com os movimentos sociais. Todavia, percebemos na prática, uma situação recorrente de desilusão que nem o curso preparatório nem a contribuição das ativistas previa ou atendia.

O tema e forma de abordá-lo são tocantes e demandaram uma atenção especial para a necessidade de acolhimento das pessoas. Muitas pessoas saem da exposição emocionadas por sensações, lembranças e vivências profundas. Sobretudo as visitantes que passaram por experiências negativas ao parir buscam escuta acolhedora, querem conversar e contar de suas dificuldades e decepções ao perceberem que podem ter sido enganadas, levadas a fazer cesarianas desnecessárias por falsos motivos, por conveniências do sistema hospitalar, por pressão familiar ou mesmo por não terem dado, à época, o valor que a experiência poderia ter. Mediadore(a)s experientes e sensíveis para estas conversas se tornaram fundamentais.

Mesmo em muitos casos que não se tratavam de desengano, percebemos que a escuta propiciava mais diálogos do que falas bem elaboradas ou veementes. $\mathrm{O}(\mathrm{A})$ mediador(a) enfático(a) pode ter muito a dizer e convicção sobre aquilo que está defendendo, mas muitas vezes se queremos que alguém reflita, que se interesse, que se envolva com a temática o melhor é deixar despertar o interesse do que buscar o convencimento. É nesse ponto que entendemos que a função de mediador(a) devia ser pensada a partir das características do trabalho das doulas ${ }^{9}$.

Juntamente com provocações e questionamentos, uma das informações que a exposição traz é a da figura da enfermeira obstetra e da doula, ainda desconhecidas pela grande maioria do(a)s visitantes. Dentre as personagens dos vídeos da seção Controvérsias, há uma atriz representando uma doula que se apresenta assim: "Doulas são mulheres que cuidam de mulheres no parto... Eu apoio e dou conforto neste momento", "Doulas não são parteiras, mas mulheres experientes que

\footnotetext{
${ }^{9}$ Segundo Silva et al. (2012), doula é a mulher que dá suporte físico, emocional, social e espiritual, fornecendo também orientações às parturientes durante o trabalho de parto, parto e pós-parto.
} 
apoiam parturientes na hora do parto, dando conforto e proporcionando o bem-estar”. Essa atuação vem sendo reforçada por evidências científicas. Conforme mostrado por Bohren et al. (2017), a presença de uma doula reduz em $60 \%$ os pedidos por anestesia, $50 \%$ a taxa de cesáreas, $40 \%$ o uso de ocitocina sintética, $20 \%$ o tempo de duração do trabalho de parto, reduz o uso de intervenções médicas em geral e aumenta a satisfação da mulher com o próprio parto, diminuindo assim as taxas de depressão pós-parto.

O acolhimento é algo fundamental, e ao tentar caracterizar isso chegamos à ideia da mediadoula, pois vimos que a função das doulas tem muita relação com a mediação:

- A doula faz parte de uma equipe multidisciplinar e tem uma atuação específica e muito especial junto à parturiente. Também, em uma exposição, vário(a)s profissionais estão envolvidos, desde a sua concepção até a montagem, mas são o(a)s mediadore(a)s que acompanharão o(a)s visitantes no momento da visita, no contato com a 'novidade', com o inesperado, com a surpresa;

- O trabalho de parto tem um tempo que depende de cada mulher e de cada bebê que vai nascer. A doula precisa ter calma, tranquilidade, saber respeitar a mulher nesse processo, pois cada mulher é particular, assim como cada visitante, que precisa de um tempo para lidar com aquilo que está em exibição. Esperamos que o(a) mediador(a) tenha sensibilidade para dar tranquilidade e conforto ao(à) visitante, respeitando o tempo necessário para a visitação e reflexão;

- Para a doula cada dia é uma vivência nova, já que as mulheres têm histórias e experiências diferentes que precisam ser acolhidas. Por que não pensar o mesmo do(a)s visitantes? Nossa experiência em museus nos indica que é comum mediadore(a)s se sentirem muito motivado(a)s nas primeiras semanas ou meses de trabalho, mas a partir daí corre-se um grande risco de o trabalho de mediação ficar automático e o(a) mediador(a) se entediar com a tarefa de mostrar a exposição que, na percepção dele(a), é sempre igual e repetitiva. A mediadoula suscita outro tipo de postura, já que tem como princípio o entendimento de que a exposição é a mesma, mas a relação que cada visitante vai estabelecer com ela será sempre diferente, já que o foco e interesse será no(a) visitante ${ }^{10}$;

${ }^{10} \mathrm{O}$ suporte social faz parte do trabalho das doulas que "favorece ambiente tranquilo, mantém o foco e o interesse na parturiente" (SILVA et al., 2012, s/p). 
- A doula também é responsável por informar, orientar e tirar dúvidas da parturiente e do(a) acompanhante, sobre procedimentos, intervenções e termos técnicos (SILVA et al., 2012). A mediadoula também terá essa função, lembrando-se sempre que esta prática não tem como objetivo transmitir conteúdos esperando que sejam devidamente assimilados pelo(a) visitante. Ao contrário, o seu conhecimento deverá servir para ampliar o debate sobre o tema e aumentar as possibilidades de participação do público.

Os pontos destacados anteriormente são fundamentais para se pensar a mediação em alguns espaços da exposição, como na seção Loja de conveniências. É preciso ter sensibilidade para não tratar de forma desrespeitosa as experiências de cesárea ou do consumo de itens dessa seção que, mesmo sendo fúteis ou absurdos, podem ter sido importantes para quem viveu determinada experiência. Muitas vezes essa nem sempre foi uma escolha autônoma, mas resultados de pressões de familiares, de médico(a)s ou de amigo(a)s, do sistema organizado para programar e controlar o nascimento. É importante pensarmos que os produtos expostos na Loja de conveniências têm intencionalidades e, no caso da Sentidos do Nascer, visam provocar deslocamentos. Isso causa um efeito muito diferente de exposições em que apresentam um único ponto de vista a fim que o visitante saia com a sensação de ter constatado um fato, em vez de se sentir envolvido na discussão e disposto a conversar mais sobre a temática em questão.

Se tentamos promover uma mudança de percepção, se tocamos em histórias e projeções pessoais de vida dos(as) visitantes, mais do que querer apregoar, ensinar, devemos buscar acolher. Isso não quer dizer evitar ponderações, mas tentar entender seus pontos de vista. Solidarizar-se com experiências ruins que tiveram que passar, alegrar-se com as boas.

Se por um lado nos esforçamos para acolher o(a)s visitantes em suas narrativas, por outro nos sentimos extremamente correspondidos por ele(a)s. Houve uma surpreendente quantidade de registros no livro de depoimentos à saída da exposição e no Facebook ${ }^{11}$. Somente nos primeiros 5 meses de exposição, os livros tiveram 2090 comentários, muitos deles longos e profundos, uma média de 1 para a cada 8 visitantes que assinaram o livro de entrada.

\footnotetext{
${ }^{11}$ Mantivemos até o final de 2015 uma página e um perfil no Facebook, com mais de 60 mil seguidores. A página tem um tom institucional, com postagens e fotos produzidas pela equipe do projeto. Já o perfil era bem mais livre. Muitos visitantes postavam ali suas fotos e faziam comentários à vontade. Uma mudança na política do Facebook impedindo perfis que não fossem vinculados a pessoas, implicou, infelizmente, no cancelamento do perfil Sentidos do Nascer com milhares de registros.
} 
Figura 5 - A identificação no Livro de Visitantes, era obrigatório à entrada da exposição. Já os registros no Livro de Depoimentos, realizados à saída, eram livres.

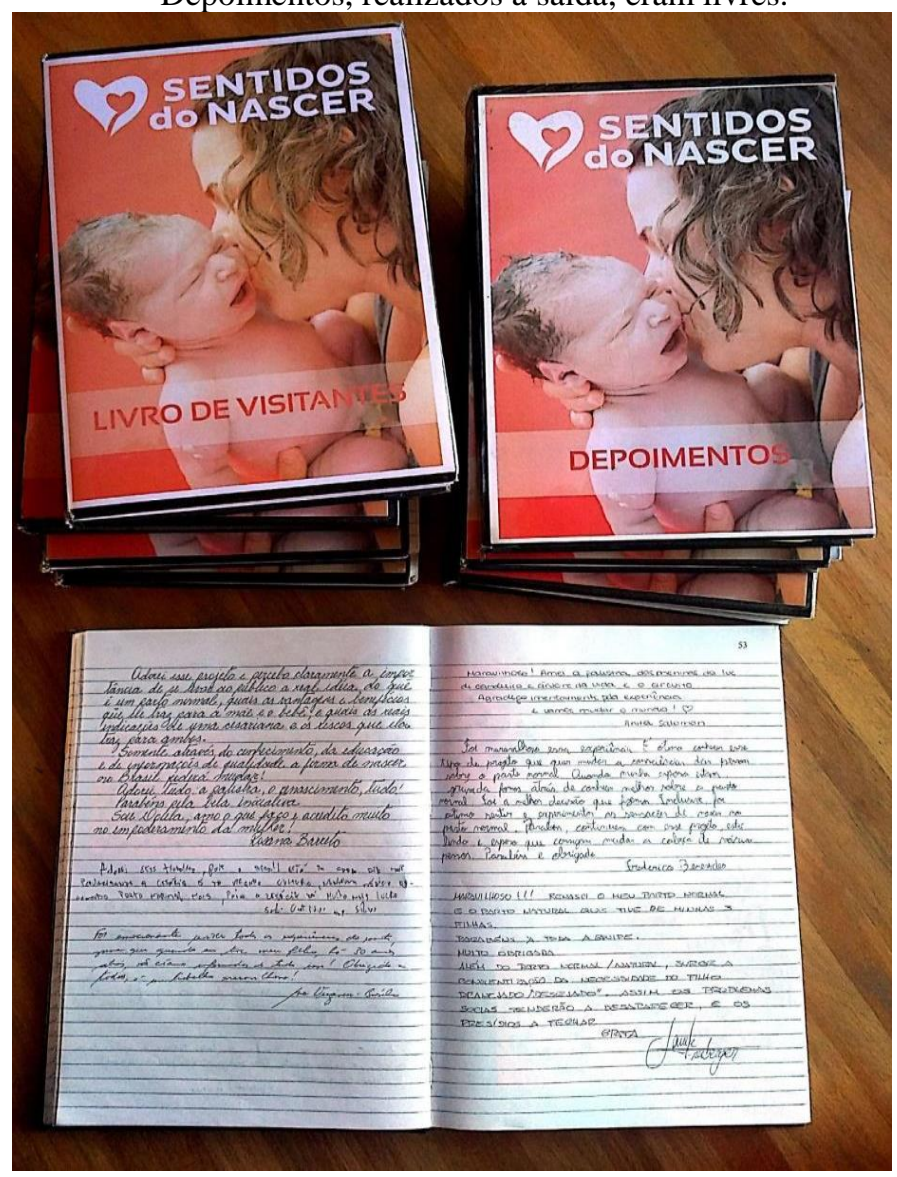

Fonte: Exposição Sentidos do Nascer.

Muitos depoimentos são realmente emocionantes, mas para ilustrar o que estamos querendo enfatizar na postura da mediadoula selecionamos esse relato de parto postado no Facebook da exposição:

Ao completar dois anos do nascimento do meu filho, fui visitar a exposição Sentidos do Nascer e senti novamente o que era ser aquela gestante. Parecia que tinha sido ontem, os sentimentos ainda estavam em mim. Saí da exposição segurando um choro apertado. Uma mocinha veio e gentilmente me perguntou se eu poderia dar um depoimento para a UnbTv. Eu disse que não seria uma boa hora, senão eu choraria. E chorei. Uma outra moça da exposição veio então conversar comigo. Pela emoção, pela fragilidade, eu não consegui explicar. Não, não sofri violência obstétrica, mas, sim, esse ainda é um assunto delicado pra mim. Ela só me disse que ajuda muito escrever o relato de parto, para então liberar algumas sombras. E nos dias seguintes, fui me perguntando o porquê de ter me abalado, de ter me recusado a dar a entrevista, afinal tenho tantas coisas pra falar. Ainda acho que não seria uma boa hora, pois não sabia muito bem o que tinha acontecido ali. Como toda grande expectativa criada, o tombo emocional é maior. Racionalmente agradeço tudo que aconteceu, mas emocionalmente há um processo de luto por um sonho não realizado (como qualquer sonho). Não vim maldizer a cesárea, nem o destino, nem o que quer que seja. Venho somente compartilhar o meu aprendizado com outras gestantes e também, com profissionais de saúde que atendem essas gestantes. Aprendi muito com relatos

Rev. Iberoam. Patrim. Histórico-Educativo, Campinas (SP), v. 4, n. 2, p. 325-342, jul./dez. 2018 
alheios e espero poder gerar nem que seja uma pequena reflexão. As gestantes tendem ser seres sensíveis, inseguras e só querem o bem de seus bebês. Somos vulneráveis às opiniões alheias e quando queremos correr contra a maré, há a enorme chance de nos tornarmos militantes. Não porque seremos irracionais em caso de complicações na hora do parto ou porque somos egoístas em querer parir a todo custo (Não! Isso são apenas julgamentos). Penso que não deveríamos ter receio em sermos enganadas por um profissional de saúde. "o processo não deveria ser tão penoso, não deveríamos ter que nos armar até os dentes de informação para defender nosso direito em ter um parto natural. Fui percebendo que o sistema de saúde não era nada receptivo às mulheres parirem em paz. Isso me deu medo, me deu indignação e me fez ficar na defensiva. Não trabalhei emocionalmente a possibilidade de uma cesárea necessária. Nem eu queria me desanimar. Pensar na possibilidade da cesárea naquele momento seria me dar permissão, caso EU achasse que não daria conta. Agora como MÃE, vejo que o meu processo de pesquisa e empoderamento poderia ser bem mais suave, sem tanta luta... Informar-se é necessário, mas ter FÉ e ENTREGA é ainda mais! Absolutamente não temos controle sobre nada. Então, como CIDADÃ, gostaria de tentar melhorar o NASCER nesse país. Informem nossa população! Que tornem o sistema de saúde cada vez mais receptivo e humanizado no atendimento às mães. Que se permita o desenrolar natural de um trabalho de parto! Obrigada por acessar a minha gestante interior e me inspirar a escrever. Desejo a todas as gestante que aproveitem essa grande oportunidade de autoconhecimento que é a maternidade. Abraços fraternos! Marcela". (comentário em <https://www.facebook.com/sentidosdonascer/>, 01 dez. 2015).

Essa história representa o alcance da expectativa inicial da exposição, de sensibilização e promoção de encontros sensíveis. Essa visitante encontrou alguém da exposição que fez um comentário delicado e inspirador... "Só disse que ajuda muito escrever...". Há muitas formas de acolher: acolher com uma única frase, nesse caso, mostrou que a escuta, a observação e a sensibilidade para perceber o(a) visitante são princípios fundamentais no trabalho de mediação. Pode-se também acolher o público na entrada de uma exposição, convidando-o para entrar, para conhecer o ambiente, deixando-o à vontade para fazer o seu percurso. Como o espaço da exposição Sentidos do Nascer comporta pequenos grupos por vez, eram bastante comuns as filas de espera na porta. O momento de espera para iniciar o percurso pode ser também uma boa oportunidade para se iniciar uma conversa, procurando conhecer o que levou aquela pessoa à exposição. Já na saída uma maneira de abordar o(a)s visitantes era a pergunta sobre o que gostou, o que não gostou e o porquê.

Assim como a doula, que compartilha as suas experiências de parto com a parturiente, a mediadoula também conhece mais sobre o assunto tratado na exposição e, por isso, está ali para compartilhar os seus saberes. No entanto, não se pode esquecer de quem é o protagonismo na situação. A mediadoula apoia o(a) visitante, gera situações e condições para que ele(a) se destaque, se sinta valorizado(a) e acolhido(a) em suas dúvidas e colocações durante a visita. 
Acreditamos que não há uma receita ou regra geral, cada um(a) desenvolve de uma maneira - o seu jeito de mediar - no qual se sente melhor. E isso não é estático. O jeito de cada um(a) mediar certamente sofrerá alterações, será revisto e aprimorado, com o acúmulo de experiências e com a troca de experiências com outro(a)s colegas e com o(a)s visitantes. Um dos maiores desafios do trabalho é evitar o desgaste da repetição, pois se a experiência repetida cria algumas facilidades, ela também traz o risco de ser tornar mecânica e sem graça. Há um dito antigo: a força do sábio (e dos educadores) está em saber dizer o já dito com o mesmo vigor com que foi dito pela primeira vez. Há que se cuidar desse vigor e tentar coletivamente buscar estratégias para evitar o desgaste da repetição. Uma dessas estratégias é alternar as posições dos mediadores, fazer que se revezem em suas funções. Outra, mais importante, é lembrar que a visita será sempre única, tendo em vista que cada pessoa construirá um significado próprio ao conhecer a exposição.

Muitas das gestantes que visitaram a exposição são contatadas meses depois, por email ou pelo telefone, pela equipe de pesquisa do projeto Sentidos do Nascer ${ }^{12}$. Após procurar saber como foi o parto, pergunta-se sobre a lembrança da exposição e a influência sobre a sua experiência de parto. Algumas responderam: "Lembrei muito daquela vozinha pedindo para esperar". Esse é um aspecto imperceptível para muito(a)s visitantes, mas marcante para outro(a)s. Até sobre o mesmo detalhe, cada um(a) guarda uma experiência diferente.

Certa vez, quando a exposição estava montada no Parque Municipal de Belo Horizonte, notamos que um casal de meia idade ficou muito tempo sentado na área Conversas, olhando tudo à volta, depois de terem passado pelo circuito expositivo. Com muita calma, leram os painéis, assistiram vários vídeos e observavam os outros visitantes. Quando indagamos o que estavam achando, responderam: "Estamos tentando entender o nosso filho. Ele veio há poucos dias com a excursão da escola e ficou muito tocado, mas não soube explicar o porquê". Também ficamos intrigados, sem saber se a experiência do filho havia sido positiva e o que o havia impressionado. Vimos, no entanto, que mesmo quando únicas e inexplicáveis, as experiências podem ser contagiantes e multiplicadoras.

$12 \mathrm{O}$ projeto de pesquisa-intervenção envolveu profissionais, professores, doutorandos e bolsistas de iniciação científica da áreas de educação, medicina, enfermagem, design e artes plásticas. Maiores detalhes em $<$ https://sistemas.ufmg.br/siex/AuditarProjeto.do?id=47771>. 


\section{CONCLUSÃO}

Acreditamos na potência do compartilhamento e da mobilização por uma boa causa. Uma vez envolvidos, conhecendo histórias marcantes de abusos e de encontros, de desconsideração e ressignificação de um momento tão especial, dos interesses em jogo e suas implicações, não há como se abster, ficar impassível ou não se implicar. Depois de sermos afetados, impactados pelas narrativas e informações sobre a temática, acabamos nos considerando responsáveis por divulgar, difundir e multiplicar esse conhecimento. Um exemplo foi o depoimento citado da visitante Marcela que "como cidadã, gostaria de tentar melhorar o nascer nesse país", conclamando para a difusão da informação e melhoria do sistema de saúde. Assim, uma das coisas que procuramos com a exposição é estimular a participação numa causa/ luta.

Entendemos que a indagação "o que fazer agora que percebo que fui enganada?" se transforma em motivação para transformar um quadro social problemático. Percebemos com essa experiência a importância de se propor temas nos quais as pessoas possam se envolver e se sintam convidadas a participar, se não do debate, das experiências proporcionadas pela exposição.

Em que medida a atuação da mediadoula poderia interessar outros museus e exposições? Que exposições poderiam se valer dessa experiência de escuta-acolhimento? Entendemos que a escuta do(a) mediador(a) vai muito além de ouvir os relatos, as dúvidas e as considerações do(a)s visitantes. A escuta e, consequentemente, o diálogo estão relacionados ao acolhimento, a uma postura sensível do(a) mediador(a) frente às histórias de vidas e questões apresentadas por quem visita a exposição. Assim como o(a) visitante se envolve com a temática, o(a) mediador se afeta pelas narrativas de cada visitante. Acreditamos que esse envolvimento mútuo propicia a construção de diálogos acolhedores e transformadores dos sujeitos envolvidos nas exposições, diferenciadose da postura de mediação cuja a escuta configura-se como uma mera formalidade.

Possivelmente, exposições que enfatizam conteúdos disciplinares e se apoiam em um modelo de transmissão de informações, muitas vezes descontextualizadas das realidades sócio históricas prescindiram do trabalho de mediadoulas. Ainda que a experiência de escutaacolhimento seja desejável em muitas exposições, acreditamos que ela é decorrente não só de um trabalho de formação de mediadore(a)s voltado para o protagonismo do público visitante, mas é também resultado da abordagem de um assunto urgente e necessário. Tal como a necessidade de mudança da percepção da sociedade sobre o nascimento, outras questões, em que estamos todo(a)s 
participando, ainda que com nossa apatia, são inadiáveis e imprescindíveis, como os problemas de saúde pública (alimentação, por exemplo), de violências históricas e injustiças sociais, (como genocídios de jovens negro(a)s no Brasil e xenofobia ao(à)s refugiado(a)s em todo o mundo, entre tantos outros). Se a cultura pode ser entendida como disputa de representações, há campos minados em que a passagem exige atenção redobrada, e em que a consciência de nosso envolvimento não é fácil, mas uma vez tocada, nos sentimos afetados e mobilizados a difundir essa atenção.

\section{REFERÊNCIAS}

BOHREN, Meghan A. et al. Continuous support for women during childbirth. Cochrane, 6 July 2017. Disponível em: <http://www.cochrane.org/CD003766/PREG_continuous-support-forwomen-during-childbirth>. Acesso em: 20 ago. 2018.

BRASIL. Ministério da Saúde. Datasus. Disponível em: <http://datasus.saude.gov.br/sistemas-eaplicativos/eventos-v/sinasc-sistema-de-informacoes-de-nascidos-vivos>. Acesso em: 23 jun. 2018.

. Ministério da Saúde. Sentidos do nascer: percepções sobre o parto e nascimento. Brasília;

2015. 48 p. Disponível em: <http://www.sentidosdonascer.org/blog/2016/03/catalogo-daexposicao/>. Acesso em: 30 out. 2018.

CONTIER, Djana. A ação dos educadores-mediadores de museus e exposições em controvérsias sociotécnicas. 2018. 255 f . Tese (Doutorado em Educação) - Faculdade de Educação, Universidade de São Paulo, São Paulo.

DUTRA, Soraia F. A educação na fronteira entre museus e escolas: um estudo sobre as visitas escolares ao Museu Histórico Abílio Barreto. 2012. 468 f. Tese (Doutorado em Educação) Faculdade de Educação, Universidade Federal de Minas Gerais, Belo Horizonte, MG.

GONÇALVES, Taisa. Parteira $\mathbf{X}$ Doula: você sabe a diferença? Disponível em: <https://humanizandoideias.wordpress.com/tag/diferenca-entre-doula-e-parteira/>. Acesso em: 20 jul. 2017.

MARANDINO, Martha. Educação em museus: a mediação em foco. São Paulo: Geenf / FEUSP, 2008.

NASCIMENTO, Silvania S. A Relação Museu e Escola: um duplo olhar sobre a ação educativa em seis museus de Minas Gerais. Revista Ensino em Re-Vista, Faculdade de Educação, Universidade Federal de Uberlândia, v. 20, n. 1, p. 179-192, jan./jun. 2013. 
PALHARINI, Luciana. A história da atenção ao parto e nascimento: possibilidades dos museus como espaços de comunicação e formação sobre o tema. 2015. 264 f. Tese (Doutorado em Educação) - Faculdade de Educação, Universidade Estadual de Campinas, Campinas, SP.

PEREIRA, Júnia et al. Escola e Museus: diálogos e práticas. Belo Horizonte: Secretaria de Estado da Cultura/ Superintendência dos Museus/ PUC-MG / Cefor, 2007.

PINTO, Simone; GOUVÊA, Guaracira. Mediação: significações, usos e contextos. Revista Ensaio, Belo Horizonte, v. 16, n. 2, p. 53-70, maio./ago. 2014.

SILVA, Raimunda Magalhães da et al . Evidências qualitativas sobre o acompanhamento por doulas no trabalho de parto e no parto. Ciênc. saúde coletiva, Rio de Janeiro , v. 17, n. 10, p. 2783 2794,Oct.2012. Disponível em <http://www.scielo.br/scielo.php?script=sci_arttext\&pid=S141381232012001000026\&lng=en\&nrm=iso>. Acesso em: 03 nov. 2018.

WAGENSBERG, Jorge. O museu "total", uma ferramenta para a mudança social. Revista História, Ciências, Saúde, Manguinhos, Rio de Janeiro, 2005. 